\title{
ВИКОРИСТАННЯ МЕТОДУ БАЛАНСУ ПОТУЖНОСТЕЙ І ІНЖЕНЕРНОГО МЕТОДУ ДЛЯ АНАЛІЗУ УСТАЛЕНОЇ СТАДІЇ ХОЛОДНОГО ЗВОРОТНОГО ВИДАВЛЮВАННЯ З РОЗДАЧОЮ
}

Для виготовлення вісесиметричних порожнистих виробів із сталей і кольорових металів в серійному і масовому виробництвах використовуються процеси холодного видавлювання. Найбільш широко розповсюджена схема зворотного видавлювання, для якої мають місце всі необхідні дані для розроблення технології і штампового оснащення та розрахунків параметрів таких процесів $[1,2]$. Зниження зусилля видавлювання забезпечує застосування схеми прямого видавлювання з роздачою [3-6]. У вказаних джерелах також приведені відомості для проектування технології та розрахунків параметрів. В останній час для виготовлення порожнистих виробів використовують схему зворотного видавлювання з роздачею в рухомій матриці, яка крім зниження зусилля видавлювання забезпечує достатньо просте видалення виробу із штампа $[7,8]$. Однак для такої схеми відсутні аналітичні залежності для визначення зусилля видавлювання, питомих зусиль на деформуючому інструменті та межі текучості здеформованого металу.

Метою роботи є використання методу балансу потужностей та інженерного методу для аналізу зворотного видавлювання з роздачею в рухомій матриці і отримання аналітичних залежностей для визначення зусилля, питомих зусиль та зміцнення здеформованого металу, а також проведення чисельного експерименту для перевірки адекватності результатів розрахунків.

Схема зворотного видавлювання з роздачею в рухомій матриці вісесиметричних порожнистих виробів конусним пуансоном приведена на рис. 1. Ліворуч від вісі симетрії наведене положення на початку видавлювання, праворуч - в кінці видавлювання. Вихідна заготовка 1, діаметр якої менший за зовнішній діаметр виробу, встановлена в матриці 2 на виштовхувачі 3. Зусилля видавлювання $P_{\partial}$ прикладається за допомогою пуансона 4. При опусканні пуансона 4 із швидкістю $V_{o}$ виконується формоутворення виробу 5. При видавлюванні матриця 2 також зміщується вниз із швидкістю $V_{o}$. Процес зворотного видавлювання з роздачею в рухомій матриці спочатку має неусталену стадію, на якій зусилля видавлювання зростає і досягає максимального значення, та усталену стадію 3 практично постійною величиною зусилля видавлювання [7]. Усталена стадія виникає, коли метал заповнює зазор між калібруючим пояском торця пуансона діаметром $D_{n}$ і циліндричною поверхнею матриці діаметром $D_{\partial}$.

Розрахункова схема для аналізу усталеної стадії методом балансу потужностей і інженерним методом зображена на рис. 2. Використання двох методів обумовлене наступним. Врахування впливу тертя на зусилля видавлювання при зміщенні об'ємів заготовки, які не деформуються, забезпечує метод балансу потужностей. Інженерний метод дозволяє виявити напруження в осередку деформації, встановити нормальні напруження на контактуючих поверхнях та точніше врахувати вплив тертя по Кулону при визначенні потужностей на подолання сил тертя. У здеформованій заготовці виділяємо осередок деформації між пуансоном і матрицею, який обмежений радіусами $R$ і $r$ та кутом $\lambda$. Стінка заготовки та частина iї, яка знаходиться нижче дуги радіусом $R$ не деформуються. В сферичній системі координат в осередку деформації виникають напруження $\sigma_{\varphi}, \sigma_{\rho}$ та $\sigma_{\theta}$. На контактуючих поверхнях в осередку деформації діють дотичні напруження $\tau_{\kappa} \mu$ ( $\varphi_{\varphi} \sigma \mu=-$ коефіцієнт тертя). 
Для знаходження радіусів $R$ i $r$ необхідно визначити кути $\lambda$ i $\gamma$.3 трикутника oic можемо знайти кут $\beta-\alpha=\beta)(+\alpha-\pi-=\pi \lambda$. Кут $\gamma$ знаходимо із рівнобедреного трикутника $o a b: \beta)(-\alpha-=\pi \gamma / 2$. Із подібності трикутників oab і odc маємо:

$$
R d c=r a b
$$

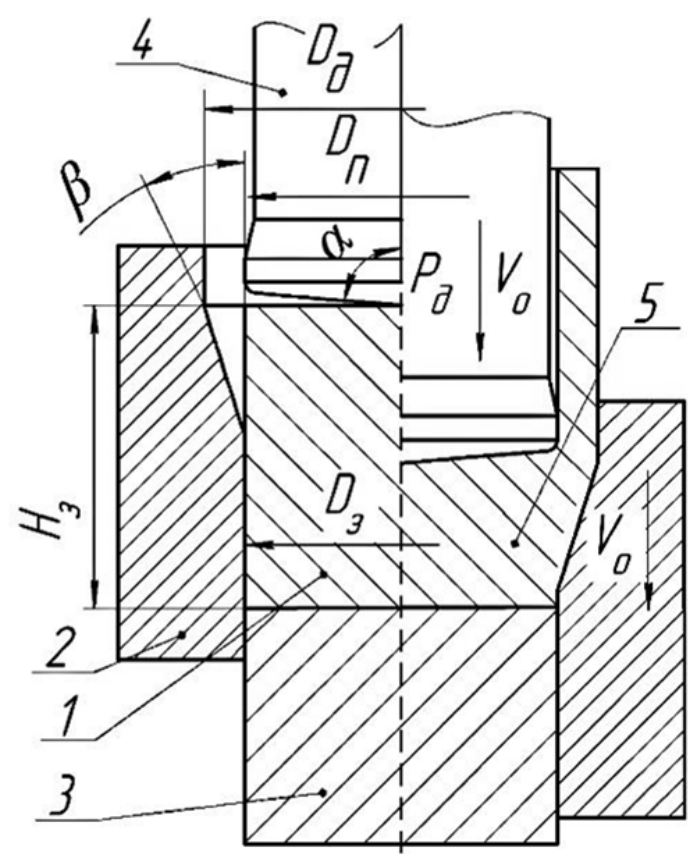

Рис. 1. Схема видавлювання з роздачею в рухомій матриці порожнистих виробів

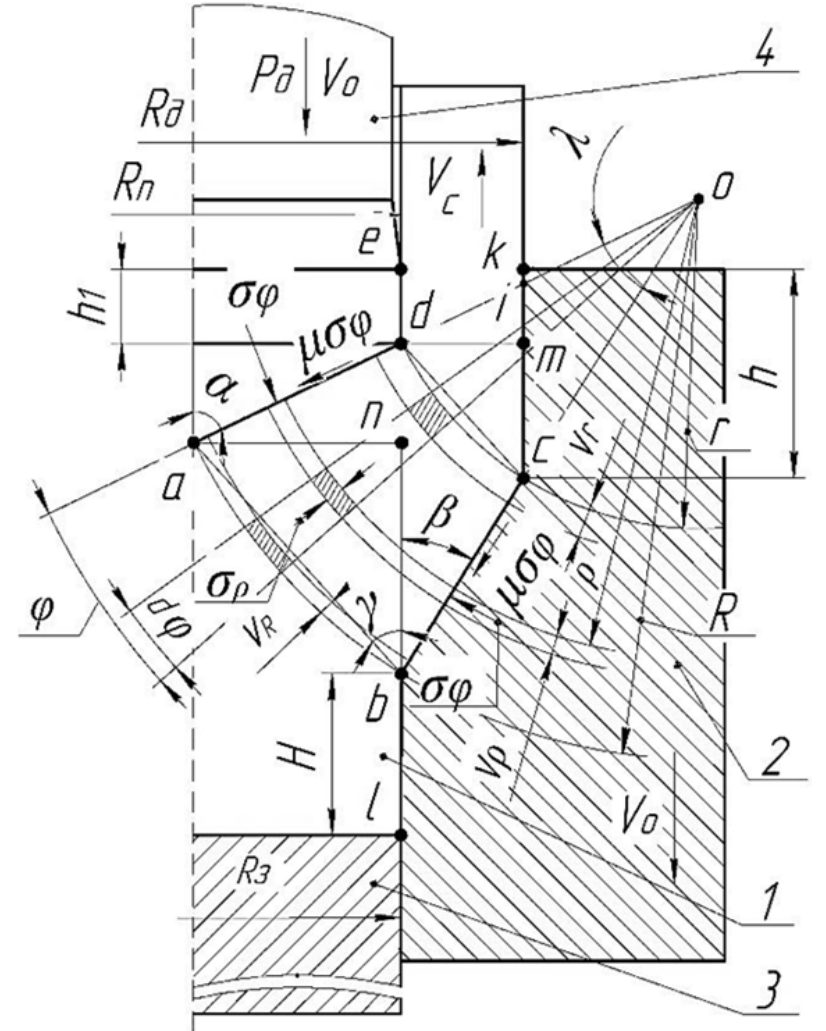

Рис. 2. Розрахункова схема для аналізу методом балансу потужностей і інженерним методом

Величину $a b$ находимо через радіус заготовки $R_{3}$ із трикутника $a n b$, а величину $d c-$ через зовнішній радіус деталі $R_{\partial}$ та радіус пуансона $R_{n}$ із трикутника $d m c: a b=R_{3} / \sin \gamma$ та $d c=\left(R_{\partial}-R_{n}\right) / \sin \gamma .3$ іншої сторони:

$$
R=r+d a=r+R_{n} / \sin \alpha .
$$

Підставляємо величини $a b, d c$ і $R$ в (1) та отримуємо вираз для знаходження радіуса $r$ :

$$
r=R_{n}\left(R_{\partial}-R_{n}\right) /\left(R_{3}-R_{\partial}+R_{n}\right) \sin \alpha
$$

Із формули (2) з урахуванням (3) маємо:

$$
R=R_{n} R_{3} /\left(R_{3}-R_{\partial}+R_{n}\right) \sin \alpha
$$

Таким чином, розміри осередку деформації визначені по розмірах деформуючого інструмента і заготовки.

Рівняння балансу потужностей для наведеної схеми має вигляд:

$$
N_{3 c}=N_{d}+N_{m}^{a d}+N_{m}^{b c}+N_{m}^{e d}+N_{m}^{c k}+N_{m}^{b l}+N_{3 b}^{d c}+N_{3 b}^{a b},
$$


де $N_{3 с}$ - потужність зовнішніх сил;

$N_{d}$ - потужність, яка витрачається на подолання опору деформування;

$N_{m}^{a d}$ - потужність, яка витрачається на подолання сил тертя на контактуючій конусній поверхні заготовки з пуансоном;

$N_{m}^{b c}$ - потужність, яка витрачається на подолання сил тертя на контактуючій конусній поверхні матриці;

$N_{m}^{e d}$ - потужність, яка витрачається на подолання сил тертя на контактуючій циліндричній поверхні пуансона і заготовки;

$N_{m}^{c k}$ - потужність, яка витрачається на подолання сил тертя на контактуючій циліндричній поверхні матриці вище осередку деформації;

$N_{m}^{b l}$ - потужність, яка витрачається на подолання сил тертя на контактуючій циліндричній поверхні матриці нижче осередку деформації;

$N_{36}^{d c}-$ потужність, яка витрачається на подолання сил зсуву на границі осередку деформації радіусом $r$;

$N_{36}^{a b}$ - потужність, яка витрачається на подолання сил зсуву на границі осередку деформації радіусом $R$.

Визначимо величини окремих складових рівняння (5). Для цього вважаємо, що на усталеній стадії видавлювання деформація відбувається за рахунок стискання металу між конусними поверхнями пуансона і матриці (деформація $\varepsilon_{\varphi}$ ) та течії в радіальному напрямку (деформація $\varepsilon_{\rho}$ ). При визначенні потужностей приймаємо, що розмір осередку деформації в окружному напрямку дорівнює одиниці. Потужність на подолання опору деформування визначається по відомій формулі:

$$
N_{\partial}=\iiint_{V} \xi_{i} \sigma_{S} d V
$$

де $\xi_{i}$ - інтенсивність швидкостей деформацій;

$\sigma_{s}$ - напруження текучості;

$d V$ - елементарний об'єм.

Спочатку вважаємо, що зміцнення відсутнє і напруження $\sigma_{s}$ постійне. Оскільки в осередку деформації течія металу проходить по радіусах то зсувні швидкості деформацій дорівнюють нулю, а швидкості деформацій $\xi_{\varphi}$ i $\xi_{\rho} \in$ головними. Тоді для плоскої деформації $\xi_{\rho}=-\xi_{\varphi}$ і $\xi_{i}=(2 / \sqrt{3}) \varepsilon_{\varphi}$. Якщо швидкості частинок металу в радіальному напрямку біля нижньої границі осередку деформації позначити через $\vartheta_{r}$, то на довільному радіусі $\rho$ маємо $\vartheta_{r} \lambda r=\vartheta_{\rho} \lambda \rho$. Звідки:

$$
\vartheta_{\rho}=\vartheta_{r} r / \rho
$$

На границі осередку деформації радіусом $R$ швидкості частинок металу мають величину $\vartheta_{R}=\vartheta_{r} r / R$. По швидкості $\vartheta_{\rho}$ можна знайти швидкість деформацій $\xi_{\varphi}=\vartheta_{\rho} / \rho=\vartheta_{r} r / \rho^{2}$. 
Елементарний об’єм елемента на довільному радіусі $\rho$ з урахуванням, що розмір осередку деформації в окружному напрямку дорівнює одиниці, має вигляд: $d V=\rho \lambda d \rho$. Після підстановки отриманих величин в рівність (6) та проведення інтегрування получаємо:

$$
N_{\partial}=(2 / \sqrt{3}) \sigma_{s} r \lambda \vartheta_{r} \int_{r}^{R} d \rho / \rho=(2 / \sqrt{3}) \sigma_{s} r \lambda \vartheta_{r} \ln (R / r) .
$$

Далі визначаємо потужності на подолання сил тертя. Для врахування тертя по Кулону напруження $\sigma_{\varphi}$ отримаємо з рішення наближених диференційних рівнянь рівноваги в сферичних координатах (без врахування дотичних напружень та використанням умови, що $\sigma_{\varphi}=\sigma_{\theta}$ ) спільно з умовою пластичності. В таких координатах маємо рівняння рівноваги $r d \sigma_{\rho} / d \rho+2\left(\sigma_{\rho}-\sigma_{\varphi}\right)=0$ і умову пластичності $\sigma_{\rho}-\sigma_{\varphi}=\sigma_{s}$.

Після інтегрування та визначення довільної постійної із умови, що при $\rho=r$ напруження $\sigma_{\rho}=0$, знаходимо $\sigma_{\rho}=-\sigma_{s} 2 \ln \frac{\rho}{r}$. 3 умови пластичності знаходимо напруження $\sigma_{\varphi}$ :

$$
\sigma_{\varphi}=\sigma_{\rho}-\sigma_{s}=-\sigma_{s}(1+2 \ln \rho / r) .
$$

По виразу для $\sigma_{\varphi}$ можна наближено оцінити розподіл питомих зусиль на пуансоні і матриці. Для подальшого спрощення рішення (без використання інтегрування) при визначенні потужностей на подолання сил тертя будемо знаходити середнє значення напруження $\sigma_{\varphi}$ i швидкостей частинок металу на контактуючих поверхнях. Середнє значення напруження $\sigma_{\varphi}$ :

$$
\sigma_{\varphi}^{c p}=\left(\sigma_{\varphi}, \text { при } \rho=r+\sigma_{\varphi}, \text { при } \rho=R\right) / 2=-\sigma_{s}(1+\ln R / r) .
$$

Середнє значення швидкості частинок металу по поверхні пуансона:

$$
\vartheta_{n}^{c p}=\left(\vartheta_{r}+\vartheta_{R}\right) / 2=(1+r / R) \vartheta_{r} / 2
$$

Пуансон зміщується зі швидкістю $\vartheta_{0}$. Радіальна складова швидкості точок пуансона дорівнює $\vartheta_{O} \cos \alpha$. Тоді для визначення потужності на подолання сил тертя на контактуючій поверхні пуансона необхідно використовувати наступну швидкість:

$$
\vartheta_{n}^{c p}=0,5(1+r / R) \vartheta_{r}+\vartheta_{o} \cos \alpha
$$

3 використанням виразів (10) і (11) та з урахуванням абсолютної величини $\sigma_{\varphi}^{c p} \mathrm{i}$ довжини контактуючої поверхні $R-r$ знаходимо:

$$
N_{m}^{a d}=\mu \sigma_{s}(1+\ln R / r)(R-r)\left[0,5(1+r / R) \vartheta_{r}+\vartheta_{o} \cos \alpha\right] .
$$

Середнє значення швидкості частинок металу на конусній поверхні матриці однакові із середнім значенням на пуансоні. Тоді потужність $N_{m}^{b c}$ має вигляд:

$$
N_{m}^{b c}=\mu \sigma_{S}(1+\ln R / r)(R-r)(1+r / R) 0,5 \vartheta_{r}
$$

При визначенні потужності, яка витрачається на подолання сил тертя на контактуючій циліндричній поверхні матриці вище осередку деформації $N_{m}^{c k}$, крім швидкості переміщення стінки $\vartheta_{c}$ необхідно також врахувати опускання матриці зі швидкістю $\vartheta_{o}$. Дотичне 
напруження на цій поверхні беремо по Зібелю у вигляді $\tau_{\kappa}=\mu \sigma_{s}$. Тоді знайдемо вказану потужність з урахуванням довжини контактуючої поверхні $h=h_{1}+\left(R_{\partial}-R_{n}\right) / \operatorname{tg} \gamma$ :

$$
N_{m}^{c k}=\mu \sigma_{s}\left[h_{1}+\left(R_{\partial}-R_{n}\right) / \operatorname{tg} \gamma\right]\left(\vartheta_{c}+\vartheta_{O}\right)
$$

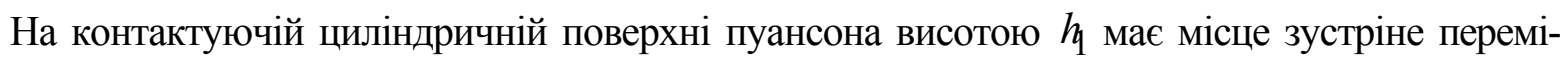
щення стінки здеформованої заготовки із швидкістю $\vartheta_{c}$ та переміщення пуансона із швидкістю $\vartheta_{0}$. Потужність, яка витрачається на подолання сил тертя на цій поверхні, має вигляд:

$$
N_{m}^{e d}=\mu \sigma_{s} h_{1}\left(\vartheta_{c}+\vartheta_{o}\right)
$$

На контактуючій циліндричній поверхні матриці висотою $H$ сили тертя виникають від переміщення матриці зі швидкістю $\vartheta_{O}$ по недеформованій частині заготовки. На подолання цих сил потрібно витратити потужність:

$$
N_{m}^{b l}=\mu \sigma_{S} H \vartheta_{O}
$$

Далі переходимо до визначення потужностей на подолання сил зсуву на границях осередку деформації. Величину дотичного напруження зсуву $\tau_{3 в}$ візьмемо, як максимально можливу найбільшу величину при пластичній деформації у вигляді $\tau_{3 в}=\sigma_{S} / 2$. Оскільки в осередку деформації має місце радіальна течія металу, то на границях радіусом $r$ i $R$ змінюється траєкторія швидкостей $\vartheta_{r}$ і $\vartheta_{R}$ на кут $\varphi$ та виникають дотичні складові відповідно $\vartheta_{r}^{\varphi}=\vartheta_{r} \operatorname{tg} \varphi$ і $\vartheta_{R}^{\theta}=\vartheta_{R} \operatorname{tg} \varphi$. При цьому кут $\varphi$ змінюється від $\varphi=\alpha$ біля поверхні контакту з пуансоном до $\varphi=\beta$ біля поверхні контакту з матрицею. Середня величина дотичних швидкостей може бути визначена по величині середнього кута $\varphi_{c p}=(\alpha-\beta) / 2$. 3 урахуванням раніше визначеної величини $\vartheta_{R}$ та кута $\lambda$ визначаємо потужності $N_{38}^{d c}$ і $N_{38}^{a b}$ :

$$
\begin{gathered}
N_{3 B}^{d c}=0,5 \sigma_{s} r \lambda \vartheta_{r} \operatorname{tg} 0,5(\alpha-\beta)=0,5 \sigma_{s} r(\alpha-\beta) \vartheta_{r} \operatorname{tg} 0,5(\alpha-\beta) ; \\
N_{3 b}^{a b}=0,5 \sigma_{s} R \lambda \vartheta_{R} \operatorname{tg} 0,5(\alpha-\beta)=0,5 \sigma_{s} R(\alpha-\beta) \vartheta_{r} \frac{r}{R} \operatorname{tg} 0,5(\alpha-\beta)= \\
=0,5 \sigma_{s} r(\alpha-\beta) \vartheta_{r} \operatorname{tg} 0,5(\alpha-\beta) .
\end{gathered}
$$

Потужність зовнішніх сил $N_{3 c}$ виразимо через нормальне напруження на пуансоні $\sigma_{\varphi}^{n}$, напрям дії якого співпадає з напруженням $\sigma_{\varphi}$ :

$$
N_{3 c}=\sigma_{\varphi}^{n}(R-r) \vartheta_{O} \sin \alpha
$$

В формули для потужностей входять швидкості $\vartheta_{r}, \vartheta_{c}$ і $\vartheta_{o}$. Швидкості $\vartheta_{r}$ і $\vartheta_{c}$ визначимо через швидкість $\vartheta_{0}$ із умови постійності витрат металу. По схемі (див. рис. 2) витрати в стінці $\vartheta_{c}\left(R_{\partial}-R_{n}\right)$ дорівнюють витратам під пуансоном $\vartheta_{o}(R-r)$. Звідки знаходимо швидкість $\vartheta_{C}$ :

$$
\vartheta_{c}=\vartheta_{o}(R-r) /\left(R_{\partial}-R_{n}\right)
$$

Аналогічно знайдемо швидкість $\vartheta_{r}: \vartheta_{r} r \lambda=\vartheta_{c}\left(R_{\partial}-R_{n}\right)$. 3 урахуванням (19) маємо: 


$$
\vartheta_{r}=\vartheta_{o}(R-r) / r \lambda
$$

Підставляємо отримані вирази для потужностей в формулу (5) та після проведення відповідних перетворень знаходимо:

$$
\begin{gathered}
\sigma_{\varphi}^{n}=\sigma_{s}\left\{\frac{2}{\sin \alpha \sqrt{3}} \ln R / r+\mu(1+\ln R / r)(1+R / r)\left[\frac{0,5(R-r)}{r(\alpha-\beta) \sin \alpha}+\operatorname{ctg} \alpha\right]\right. \\
+\mu(1+\ln R / r)(1+R / r) \frac{0,5(R-r)}{r(\alpha-\beta) \sin \alpha}+ \\
+\mu\left[h_{1}+\left(R_{\partial}-R_{n}\right) / \operatorname{tg} \gamma\right]\left(\frac{1}{R_{\partial}-R_{n}}+\frac{1}{R-r}\right) \frac{1}{\sin \alpha}+ \\
\left.+\mu h_{1}\left(\frac{1}{R_{\partial}-R_{n}}+\frac{1}{R-r}\right) \frac{1}{\sin \alpha}+\frac{\mu H}{(R-r) \sin \alpha}+\frac{1}{\sin \alpha} \operatorname{tg} 0,5(\alpha-\beta)\right\} .
\end{gathered}
$$

Тепер по напруженню $\sigma_{\theta}^{n}$ можна визначити зусилля видавлювання $P_{\partial}$, яке співпадає 3 напрямком переміщення пуансона:

$$
P_{\partial}=\sigma_{\varphi}^{n} \pi R_{n}(R-r) / \sin \alpha
$$

В приведеному аналізі не враховано зміцнення здеформованого металу. Для його врахування використовуємо відому апроксимацію діаграми істинних напружень другого роду у вигляді [9]:

$$
\sigma_{s}=\frac{\sigma_{B}}{1-\psi_{u}}\left(\frac{\psi}{\psi_{u}}\right)^{\psi u^{/ 1-\psi} u}
$$

де $\sigma_{B}-$ межа міцності;

$\psi_{u}$ - відносне потоншення, яке відповідає моменту утворення шийки на зразку при стандартних випробуваннях;

$\psi$ - поточне значення відносного потоншення.

Якщо в якості поточного відносного потоншення взяти зменшення довжини дуги в осередку деформації радіусом $R$ до дуги радіусом $r$, то маємо $\psi=(R \lambda-r \lambda) / R \lambda=(R-r) / R$. Тоді середня величина напруження $\sigma_{S}$ в осередку деформації розраховується при $\psi_{c p}=\psi / 2$ :

$$
\sigma_{S}^{c p}=\frac{\sigma_{B}}{1-\psi_{u}}\left(\frac{R-r}{2 R \psi_{u}}\right)^{\psi} u^{/ 1-\psi} u
$$

3 використанням виразу (23) і формули (9) можна визначити розподіл напружень $\sigma_{\varphi}$ на поверхнях пуансона і матриці, змінюючи величину $\rho$ від радіуса $r$ до радіуса $R$.

Для перевірки адекватності розрахунків по отриманих аналітичних залежностях з використанням метода скінченних елементів (MCE) в середовищі DEFORM-2D був проведений чисельний експеримент по холодному видавлюванню з роздачею в рухомій матриці вісесиметричних порожнистих виробів із сталі 10. Розміри деформуючого інструмента і заготовки були наступні (див. рис. 2): $R_{n}=10$ мм, $\alpha=83^{\circ}, h_{1}=2$ мм, $R_{3}=10$ мм, $R_{\partial}=13,7$ мм, $\beta=21,5^{\circ}$. При наведених розмірах отримано $R=16 \mathrm{Mм}, r=5,92 \mathrm{Mм}, \lambda=61,5^{\circ}, \gamma=37,5^{\circ}, h=6,8 \mathrm{Mм}$. 
Залежність зусилля видавлювання від переміщення пуансона, яка отримана за допомогою МСЕ приведена на рис. 3. Зусилля спочатку зростає повільно до моменту виходу здеформованого металу в зазор між матрицею і пуансоном (переміщення пуансона 41 мм). Далі іде інтенсивне зростання зусилля до 515 кН і при переміщенні пуансона 13 мм процес переходить в усталену стадію, на якій зусилля залишається постійним. На графіку наведена величина зусилля 466 кН (МБМ і IM), яка отримана по формулах $(21,22,24)$. Розбіжність у значеннях у значеннях зусиль на усталеній стадії складає $9,5 \%$.

Розподіл інтенсивності напружень у здеформованій заготовці наведений на рис. 4. Тонкими лініями зображений деформуючий інструмент, а розміри по вісях показані в міліметрах. В осередку деформації в дужках відмічена величини середнього напруження $\sigma_{S}^{c p}$, яке визначено по формулі (24). Розбіжність результатів складає 5,6 \%. Розподіл осьових напружень $\sigma_{z}$ у здеформованій заготовці показаний на рис. 5. На розподілі відмічені величини напружень $\sigma_{z}$ на поверхні заготовки, яка контактує з пуансоном. В дужках приведені значення проекцій напруження $\sigma_{\varphi}$ на вісь симетрії $\left(\sigma_{\varphi} / \cos \alpha\right)$, які отримані по виразах (9) i (24). Як видно, формула (9) дозволяє достатньо точно розрахувати максимальну величину напруження $\sigma_{\varphi}$, яку можна використати в якості питомого зусилля на пуансоні.

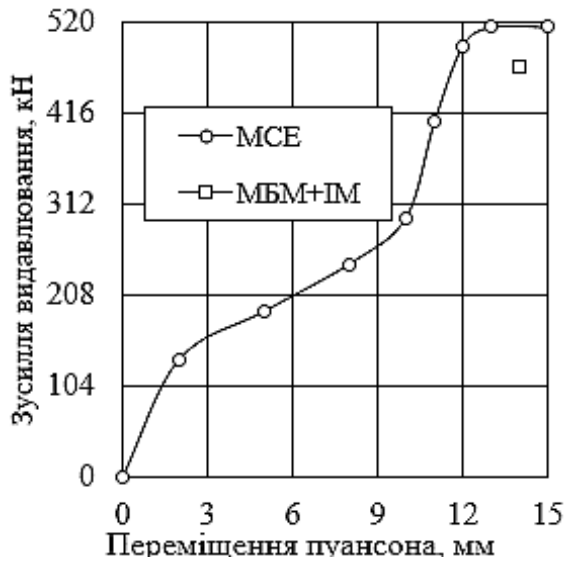

Рис. 3. Залежність

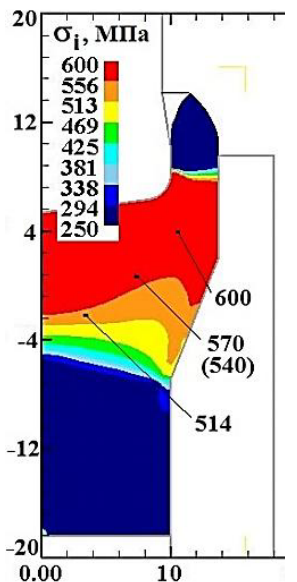

Рис. 4. Розподіл

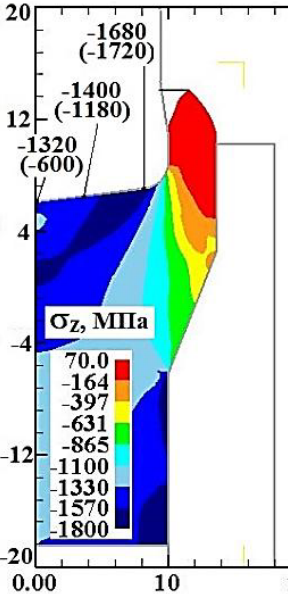

Рис. 5. Розподіл видавлювання від переміщення пуансона, інтенсивності напружень $\sigma_{i}$ осьових напружень $\sigma_{z}$ яка отримана за допомогою МСЕ

\section{ВИСНОВКИ}

Методом балансу потужностей спільно з інженерним методом виконаний аналіз усталеної стадії холодного зворотного видавлювання з роздачею в рухомій матриці вісесиметричних порожнистих виробів. Перший метод дозволяє врахувати тертя на контактуючих поверхнях між об'ємами заготовки, які не деформуються, та інструментом, а другий - забезпечує визначення нормальних напружень в осередку деформації та врахувати вплив сил тертя по Кулону при знаходженні потужностей. Отримані аналітичні залежності для розрахунку зусилля деформування, нормальних напружень на пуансоні і матриці. Враховано зміцнення металу при формоутворенні по ступеневій апроксимації діаграми істинних напружень. Для перевірки адекватності результатів по отриманих виразах з використанням МСЕ проведений чисельний експеримент по отриманню виробів конкретних розмірів. Порівняння результатів моделювання та розрахунків по формулах показали можливість застосування отриманих виразів для практичних розрахунків зусилля видавлювання, питомих зусиль та межі текучості здеформованого металу. 


\section{СПИСОК ВИКОРИСТАНОЇ ЛІТЕРАТУРИ}

1. Ковка и объемная штамповка : справочник. В 4-х т. Т. З. Холодная объемная итамповка / Ред. совет : Е. И. Семенов (пред.) и др. ; под ред. Г. А. Навроикого. - М. : Маииностроение, 1987. - 384 с.

2. Овчинников А. Г. Основы теории штамповки выдавливанием на прессах / А. Г. Овчинников. М. : Машиностроение, 1983. - 200 c.

3. Овчинников А. Г. Прямое выдавливание цилиндрических стаканов / А. Г. Овчинииков, А. В. Хабаров // Совериенствование проиессов объемной штамповки. - М. : МДНТП, 1980. - С. 103-108.

4. Дмитриев А. М. Исследование процесса выдавливания с раздачей / А. М. Дмитриев // Известия вузов. М. : Машиностроение, 1984. - № 4. - С. 140-148.

5. Гречников В. Ф. Прогрессивные технологические проиессы холодной штамповки / В. Ф. Гречников, А. М. Дмитриев, В. Д. Кухарь и др. ; под общ. ред. А. Г. Овчинникова. - М. : Машиностроение, $1985 .-184$ с.

6. Калюжный В. Л. Сравнительный анализ процессов обратного выдавливания и прямого выдавливания с раздачей изделий с полостью постоянного диаметра / В. Л. Калюжный, Л. И. Алиева, И. П. Куликов // Обработка материалов давлением : сб. науч. трудов. - Краматорск : ДГМА, 2013. - № 4(37). - С. 87-92.

7. Калюжний В.Л. Аналіз схем холодного видавлювання вісесиметричних порожнистих виробів / В. Л. Калюжний, А. М. Потятиник // Наукові нотатки. Міжсузівський збірник. - Луцььк : НТУ, 2017. - № 59. - С. $137-143$.

8. Калюжний В. Л. Визначення параметрів холодного комбінованого видавлювання вісесиметричних порожнистих напівфабрикатів із виступом у донній частині зі сторони порожнини / В. Л. Калюжний, А. М. Потятиник, Х. В. Малій // Обработка материалов давлением. - Краматорск : ДГМА, 2018. - № 2(47). C. 105-113.

9. Попов Е. А. Основы теории листовой штамповки : учеб. пособ. для вузов. - Изд. 2-е, пераб. и доп. / Е. А. Попов. - М. : Машиностроение. -278 c.

\section{REFERENCES}

1. Kovka i ob\#emnaja shtampovka : spravochnik. V 4-h t. T. 3. Holodnaja ob\#emnaja shtampovka / Red. sovet: E. I. Semenov (pred.) i dr. ; pod red. G. A. Navrockogo. - M. : Mashinostroenie, 1987. - 384 s.

2. Ovchinnikov A. G. Osnovy teorii shtampovki vydavlivaniem na pressah / A. G. Ovchinnikov. - M. : Mashinostroenie, 1983. - $200 \mathrm{~s}$.

3. Ovchinnikov A. G. Prjamoe vydavlivanie cilindricheskih stakanov / A. G. Ovchiniikov, A. V. Habarov // Sovershenstvovanie processov ob\#emnoj shtampovki. - M. : MDNTP, 1980. - S. 103-108.

4. Dmitriev A. M. Issledovanie processa vydavlivanija s razdachej / A. M. Dmitriev // Izvestija vuzov. - M. : Mashinostroenie, 1984. - № 4. - S. 140-148.

5. Grechnikov V. F. Progressivnye tehnologicheskie processy holodnoj shtampovki / V. F. Grechnikov, A. M. Dmitriev, V. D. Kuhar' i dr. ; pod obshh. red. A. G. Ovchinnikova. - M. : Mashinostroenie, 1985. - 184 c.

6. Kaljuzhnyj V. L. Sravnitel'nyj analiz processov obratnogo vydavlivanija i prjamogo vydavlivanija s razdachej izdelij s polost'ju postojannogo diametra / V. L. Kaljuzhnyj, L. I. Alieva, I. P. Kulikov // Obra-botka materialov davleniem : sb. nauch. trudov. - Kramatorsk : DGMA, 2013. - № 4(37). - S. 87-92.

7. Kaljuzhnij V. L. Analiz shem holodnogo vidavljuvannja visesimetrichnih porozhnistih virobiv / V. L. Kaljuzhnij, A. M. Potjatinik // Naukovi notatki. Mizhvuzivs'kij zbirnik. - Luc'k : NTU, 2017. - № 59. - S. $137-143$.

8. Kaljuzhnij V. L. Viznachennja parametriv holodnogo kombinovanogo vidavljuvannja visesimetrichnih porozhnistih napivfabrikativ iz vistupom u donnij chastini zi storoni porozhnini / V. L. Kaljuzhnij, A. M. Potjatinik, H. V. Malij // Obrabotka materialov davleniem. - Kramatorsk: DGMA, 2018. - № 2(47). - S. $105-113$.

9. Popov E. A. Osnovy teorii listovoj shtampovki : ucheb. posob. dlja vuzov. - Izd. 2-e, perab. i dop. I E. A. Popov. - M. : Mashinostroenie. -278 s.

Калюжний В. Л. - д-р техн. наук, проф. НТУУ «КПІ ім. І. Сикорського»;

Левченко В. М. - канд. техн. наук, докторант ДДМА.

НТУУ «КПІ ім. І. Сикорського» - Національний технічний університет України «Київський політехнічний інститут імені Ігоря Сікорського», м. Київ.

ДДМА - Донбаська державна машинобудівна академія, м. Краматорськ.

E-mail: kw1_2011@ukr.net; electrosupport@ukr.net. 